\title{
Comportamento ingestivo de vacas nulíparas com diferentes pelagens em pastagem nativa no Rio Grande do Sul
}

\author{
Ingestive behavior of nulliparous cows of different hair in native pasture \\ in Rio Grande do Sul
}

Jaquesson Minuzzo Alves, Marcele Sousa Vilanova

Universidade de Caxias do Sul (UCS), Caxias do Sul, RS, Brasil

\section{Resumo}

O experimento foi conduzido em propriedade particular, localizada na região dos Campos de Cima da Serra, no município de Monte Alegre dos Campos/RS, com o objetivo de avaliar o comportamento ingestivo de vacas nulíparas. Os animais foram manejados em uma área de pastagem nativa durante o mês de janeiro de 2017 . Os tratamentos resultaram na combinação fatorial (3 x 3), de três colorações de pelagem (vermelha, baia e preta) e três turnos de avaliação (manhã, meio-dia e tarde) dispostos em um delineamento inteiramente casualizado, com três repetições. Para as avaliações foram utilizadas nove fêmeas bovinas com tendência racial europeia e peso corporal médio de $450 \mathrm{~kg}$. As observações foram realizadas através da técnica do etograma, com duração de 10 horas, sendo feitas de 10 em 10 minutos em período diurno, durante quatro dias consecutivos. As variáveis avaliadas foram: os tempos despendidos com pastejo, ruminação, caminhada, ócio, bebendo água, urinando/defecando, permanência na floresta e busca pela sombra. 0 comportamento ingestivo foi dividido em $41 \%$ pastando, 29,5\% ruminando, 13,2\% em ócio, 6,5\% caminhando, 0,8\% ingerindo água e 9\% do tempo as vacas nulíparas passaram na floresta. A pelagem e o turno influenciaram significativamente $(p<0,05)$ o comportamento ingestivo dos animais, sendo que o turno influenciou os comportamentos de pastejo, ruminação, ócio, permanência na floresta e caminhada, enquanto a pelagem influenciou os comportamentos de pastejo, ruminação e permanência na sombra. Os animais tendem a diminuir a ingestão de alimento e aumentar a taxa de ruminação no turno do meio-dia, sendo que os de pelagem preta iniciam essas atividades antes e são os animais que mais procuram a sombra durante o dia.

Palavras-chave: Bem-estar. Ruminação. Pastejo. Sombra.

\section{Abstract}

The experiment was conducted in private farm, located in the area of Campos de Cima da Serra in the municipality of Monte Alegre dos Campos/RS, in order to evaluate the ingestive behavior of nulliparous cows. The treatments were done in factorial combination ( $3 \times 3)$, three coats of 
color (red, white and black) and three times of evaluation (morning, midday and afternoon) arranged in a completely randomized design with three replicates. For the evaluations, nine female cattle with a European racial tendency and average body weight of $450 \mathrm{~kg}$ were used. Observations were made through the 10-hour etogram technique and were performed every 10 minutes during the day for four consecutive days. The variables evaluated were: time spent with grazing, rumination, walking, leisure, drinking water, urinating / defecating, staying in the forest and searching for shadow. The ingestive behavior was divided into $41 \%$ grazing, 29.5\% ruminating, 13.2\% idling, 6.5\% walking, $0.8 \%$ ingesting water and $9 \%$ of the time nulliparous spent in the forest. The coat and time of evaluation influenced the ingestive behavior of the animals significantly $(p<0.05)$, and the turn influenced the behavior of grazing, rumination, leisure, stay in the forest and walking, while the coat influenced the behavior of grazing, rumination and staying in the shadow. Animals tend to decrease feed intake and increase rumination rate in the midday, with black-haired animals initiating these activities earlier and being the animals that most seek shadow during the day.

Keywords: Welfare. Rumination. Grazing. Shadow.

\section{Introdução}

O comportamento ingestivo dos ruminantes é influenciado diretamente pelo clima, alimento, sistema de criação e fenótipo do animal a campo (Gonyou, 1994). Por meio do conhecimento dessas interações podem ser definidas as estratégias para a adequação do manejo, tanto do pasto quanto dos animais, visando a interferência positiva nos resultados da produção (Bremm et al., 2008), uma vez que a avaliação do comportamento é uma das ferramentas para percebermos as relações do animal com o ambiente em que vive (Faria et al., 2011).

O conhecimento dos padrões de comportamento de escolha, localização e ingestão do alimento pelo animal são de fundamental importância quando se pretende estabelecer práticas de manejo de animais a pasto (Del Claro, 2010).

0 animal em pastejo está sob o efeito direto da qualidade e quantidade de pastagem oferecida, sendo que $o$ ato de $o$ animal selecionar a dieta, consumindo as partes mais nutritivas da planta, quando a oferta é heterogênea, pode resultar no aumento do comportamento seletivo, promovendo aumento no tempo total de pastejo (Júnior et al., 2010).

A temperatura ambiente é outro fator que pode influenciar a ingestão da forragem, uma vez que os períodos com maior intensidade de pastejo ocorrem nas horas de temperaturas mais amenas do dia (Polli et al., 1996). 0 que motiva o início da atividade de pastejo é o nascer do sol, ficando evidente que a disponibilidade de sombra aos animais, quando as temperaturas atingirem um nível elevado, é de suma importância para evitar o estresse térmico e o comprometimento do desempenho dos animais (Broom e Frasier, 2010).

Os bovinos são animais homeotérmicos e possuem uma zona de termoneutralidade que, em animais com genótipo europeu criados em regiões temperadas, situa-se abaixo de $20{ }^{\circ} \mathrm{C}$, associada a uma umidade relativa entre 60 a $70 \%$ (Pires et al., 1999). Segundo Brown-Brandl et al. (2006), quando a temperatura ambiente está acima da zona de conforto térmico, o animal tende a procurar a sombra, evitando os efeitos da radiação solar direta e o consequente aumento do calor. Outra forma de perder calor é por meio de evapotranspiração respiratória (ofegação), sendo as principais vias a radiação de ondas longas, a convecção e a condução (Reece, 1996). Caso o animal não perca calor para o ambiente, estará em uma situação de estresse térmico, o que resultará em prejuízos econômicos ao sistema (Pires, et al., 1999).

A cor da pelagem dos animais é outro fator importante, que afeta diretamente nas trocas de temperatura com o ambiente. Animais com pelame escuro apresentam maior absorção e menor reflexão da radiação térmica, resultando em maior estresse térmico quando comparados aos de pelames claros, que apresentam maior penetração da radiação solar (Brown-Brandl et al., 2006).

Para a avaliação do comportamento ingestivo de ruminantes em criação extensiva, são considerados os tempos despendidos com as atividades de pastejo, ruminação e ócio. Segundo Júnior et al. (2010), conhecer os horários que os animais preferencialmente exercem o comportamento de pastejo é importante no momento de estabelecer estratégias para adaptar o manejo. 
0 objetivo deste trabalho foi avaliar o comportamento ingestivo diurno de vacas nulíparas de diferentes colorações de pelagem, em sistema de criação extensivo com pastagem nativa melhorada, na região dos Campos de Cima da Serra, no Rio Grande do Sul.

\section{Material e métodos}

O experimento foi desenvolvido em propriedade particular, situada no município de Monte Alegre dos Campos, região dos Campos de Cima da Serra, no estado do Rio Grande do Sul. 0 clima da região é, segundo Köppen, do tipo Cwa (mesotérmico) e definido como clima temperado chuvoso no verão e com inverno seco entre junho e setembro (Wrege, 2012). As coordenadas geográficas do local são $28^{\circ} 44^{\prime}$ de latitude sul e $50^{\circ} 50^{\prime}$ de longitude oeste. A temperatura registrada nos dias do experimento foi obtida através do site do Instituto Nacional de Meteorologia (INMET, 2017).

0 ensaio correspondeu à avaliação de nove vacas nulíparas (com aproximadamente 3 meses de gestação), todas com tendência racial europeia e peso corporal médio de $450 \mathrm{~kg}$, as quais foram alocadas em um piquete composto por pastagem à base de campo nativo sobressemeado com festuca (Festuca spp.). As observações do comportamento ingestivo ocorreram durante os dias 10,11, 12 e 13 de janeiro de 2017, utilizando o método do etograma - animal focal (Del-Claro, 2010), com intervalos de avaliação de 10 em 10 minutos, durante o período compreendido entre as $8 \mathrm{~h}$ às $17 \mathrm{~h} 50$, totalizando dez horas (600 minutos) de avaliação. Os avaliadores ficaram afastados do ambiente pastoril, evitando interferência no comportamento dos animais, e as avaliações do comportamento ingestivo foram realizadas por meio de observação visual direta (Jamieson e Hodgson, 1979).

Os tratamentos resultaram da combinação fatorial $(3 \times 3)$, com três colorações de pelagem (vermelha, baia e preta) e três turnos de avaliação de 200 minutos cada (turno da manhã: das $8 \mathrm{~h}$ às $11 \mathrm{~h}$; turno do meio dia: das $11 \mathrm{~h} 20$ às $14 \mathrm{~h} 30$; turno da tarde: das $14 \mathrm{~h} 40$ às $17 \mathrm{~h} 50$ ), em delineamento inteiramente casualizado, com três repetições.
$\mathrm{Na}$ avaliação do comportamento ingestivo, foram registrados os tempos despendidos com as atividades de pastejo (momento em que animais coletaram e levaram a forragem à boca, apreendendo e cortando as folhas e, após, realizando o movimento de $1^{\text {a }}$ mastigação e posterior deglutição), caminhada (momento em que os animais se deslocavam pelo piquete sem estarem se alimentando ou ruminando), ruminação (momento em que os animais realizaram a $2^{\text {a }}$ e efetiva mastigação do bolo alimentar, após o retorno deste à boca), ócio (momento de descanso dos animais, no qual não realizaram nenhuma outra atividade), bebendo água (momento em que os animais foram ao bebedouro e ingeriram água), defecando/urinando (momento em que, na observação, os animais realizavam a excreção de urina ou fezes) e permanência na floresta (momento em que os animais adentravam na floresta e ficaram fora do alcance para avaliação), acrescido da observação de permanência na sombra (momento em que os animais utilizavam as áreas de sombra para realizar quaisquer atividades avaliadas).

Os animais, individualizados através do uso de fitas coloridas no pescoço, foram mantidos em um piquete único de 30 hectares. 0 piquete apresentou uma área de floresta (considerada como sombra natural), onde se considerou o comportamento floresta, quando os animais entravam nela e ali permaneciam (sem visualização adequada pelos observadores). Em alguns momentos, os animais estavam fora da floresta, mas protegidos da radiação solar, pela sombra derivada das árvores, e este comportamento foi indicado como sombra. A pastagem apresentou como características uma produção de matéria seca média de $2.607 \mathrm{~kg} / \mathrm{ha}$ (amplitude de 1.326 a $6.022 \mathrm{~kg} / \mathrm{ha}$ ) e uma altura de dossel forrageiro média de $17 \mathrm{~cm}$ (amplitude de 8 a $32 \mathrm{~cm}$ ). A composição bromatológica da pastagem foi de $16 \%$ de proteína bruta e $63,41 \%$ de fibra em detergente neutro (FDN). Os animais permaneceram com acesso à água à vontade, sal mineral e sombra natural (floresta) durante todo período de avaliação.

Os resultados obtidos foram submetidos à análise de variância e as médias comparadas pelo teste Tukey a $5 \%$, através do programa estatístico Assistat 7.7 (Silva e Azevedo, 2016). 


\section{Resultados}

Durante o período experimental, a temperatura média foi de $20{ }^{\circ} \mathrm{C}$ no turno da manhã, $24{ }^{\circ} \mathrm{C}$ no turno do meio dia e $27,5^{\circ} \mathrm{C}$ no turno da tarde.

0 comportamento ingestivo geral das nulíparas ficou distribuído em $41 \%$ de atividade de pastejo, $29,5 \%$ de ruminação, 13,2\% em ócio, 9\% de permanência na floresta, 6,5\% em caminhada e $0,8 \%$ do tempo com ingestão de água.

Os comportamentos que demandam maior mobilização das funções metabólicas, como o pastejo e a caminhada, foram mais intensos no turno da manhã e no turno da tarde, sendo o turno do meio-dia reservado ao descanso e à ruminação.

As atividades comportamentais de pastejo, ruminação, ócio, permanência na floresta e caminhada apresentaram efeito significativo $(\mathrm{p}<$ 0,05 ) de acordo com o turno de avaliação (Tabela 1).

A busca pela floresta foi o único comportamento que aumentou conforme o passar das horas do dia, o que possivelmente se justifica pelo fato de o turno da tarde iniciar ainda sob efeito de alta incidência de luz solar, fazendo com que os animais seguissem buscando conforto térmico mesmo após o meio-dia.

Tabela 1 - Valores médios (em minutos) dos tempos despendidos com os comportamentos ingestivos de vacas nulíparas com relação ao turno de avaliação

\begin{tabular}{lccc|c}
\hline & Manhã & Meio-dia & Tarde & Total geral \\
\hline Pastando & $112,20^{\mathrm{a}}$ & $36,66^{\mathrm{b}}$ & $97,44^{\mathrm{a}}$ & 246,30 \\
Ruminando & $50,52^{\mathrm{b}}$ & $90,00^{\mathrm{a}}$ & $36,36^{\mathrm{b}}$ & 176,88 \\
Ócio & $11,64^{\mathrm{c}}$ & $44,70^{\mathrm{a}}$ & $22,98^{\mathrm{b}}$ & 79,32 \\
Floresta & $6,06^{\mathrm{c}}$ & $17,76^{\mathrm{b}}$ & $29,10^{\mathrm{a}}$ & 52,92 \\
Caminhando & $18,60^{\mathrm{a}}$ & $8,28^{\mathrm{b}}$ & $11,94^{\mathrm{a}}$ & 38,82 \\
Bebendo água & $0,78^{\mathrm{a}}$ & $2,46^{\mathrm{a}}$ & $1,68^{\mathrm{a}}$ & 4,92 \\
Urinando/defecando & $0,20^{\mathrm{a}}$ & $0,14^{\mathrm{a}}$ & $0,50^{\mathrm{a}}$ & 0,84 \\
\hline Total por turno & 200 & 200 & 200 & 600 \\
\hline
\end{tabular}

Nota: Letras diferentes na mesma linha diferem significativamente pelo Teste de Tukey a $5 \%$ de probabilidade.

Avaliando a distribuição dos comportamentos de pastejo, ruminação e ócio, nas horas de avaliação (Figura 1) foi observado que os picos de ruminação são intercalados com os picos de pastejo, nos quais os animais usaram efetivamente o tempo para a atividade digestiva, sendo o período de ócio expressivo apenas durante o período de maior incidência de luz solar.

A pelagem dos animais também influenciou a distribuição do comportamento de pastejo (Figura 2) e de ruminação (Figura 3). Os animais apresentaram comportamento de pastejo similares no decorrer das horas de avaliação, entretanto observou-se que os animais de pelagem preta tiveram uma tendência em diminuir a taxa de consumo de forragem a partir das $11 \mathrm{~h}$, enquanto os animais de pelagem vermelha $\mathrm{e}$ baia seguiram colhendo alimento, e ao chegar no auge do meio-dia, os animais de pelagem preta não foram observados pastando.

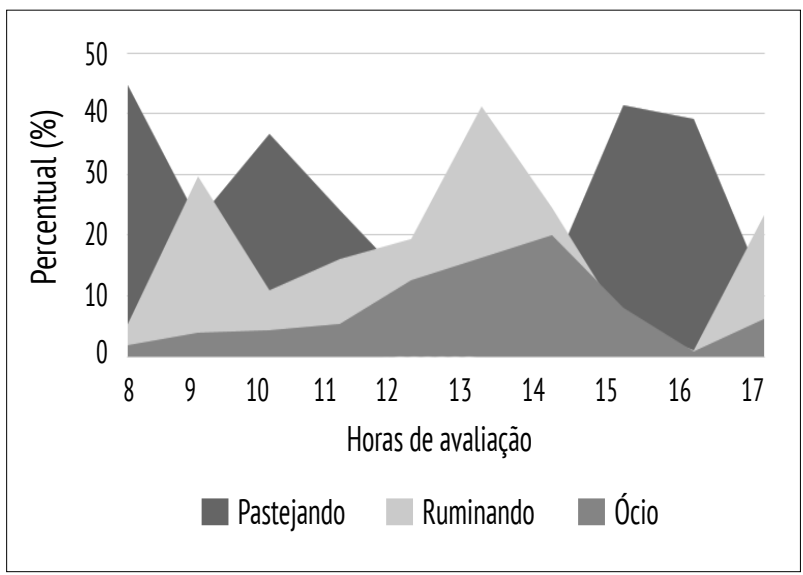

Figura 1 - Distribuição espacial em percentual (\%) dos comportamentos de pastejo, ruminação e ócio, em intervalos de uma hora, durante o período de $10 \mathrm{~h}$ de avaliação.

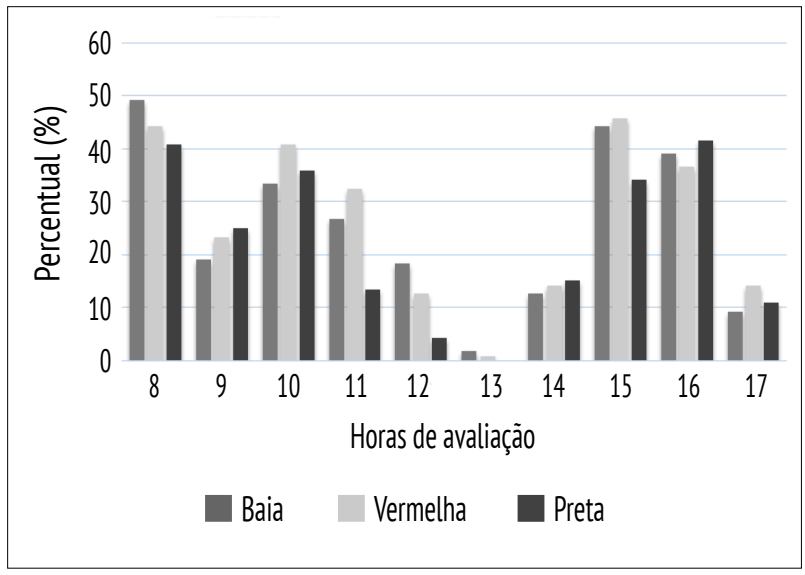

Figura 2 - Variação percentual do tempo médio despendido com o comportamento de pastejo, em intervalos de uma hora, em função da coloração da pelagem dos animais. 
Por volta das $14 \mathrm{~h}$ foi verificado aumento no pico de pastejo, quando todos os animais reiniciaram a colheita de alimentos, seguindo numa ascensão de ingestão até as $16 \mathrm{~h}$. Quando comparado o comportamento de pastejo com o de ruminação (Figura 3), observou-se uma sequência lógica e intercalada entre os dois principais comportamentos ingestivos realizados pelos ruminantes em pastejo, a qual apresenta o maior pico entre as $12 \mathrm{~h}$ e as $14 \mathrm{~h}$.

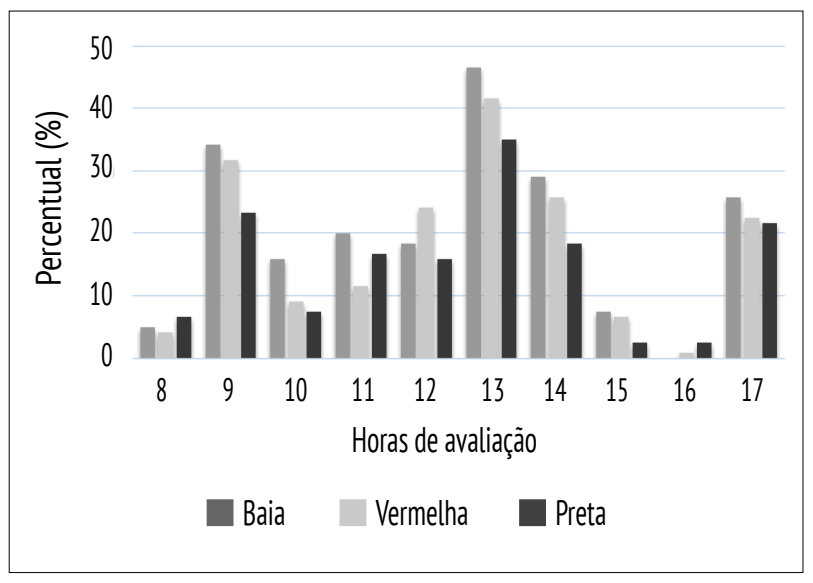

Figura 3 - Variação percentual do tempo médio despendido com o comportamento de ruminação, em intervalos de uma hora, em função da coloração da pelagem dos animais.

A pelagem e o turno (Figura 4) influenciaram a busca dos animais pela sombra, sendo que esta foi constante entre os turnos.

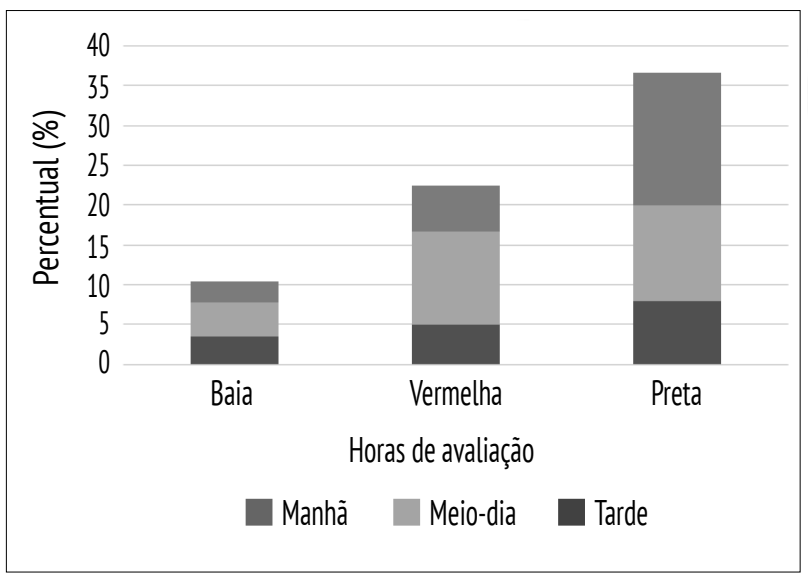

Figura 4 - Variação percentual do tempo médio de permanência na sombra, de acordo com o turno de avaliação e a coloração da pelagem dos animais.
Os animais de pelagem preta apresentaram maior pico de permanência na sombra no turno da tarde e foram os que mais procuraram essa alternativa, diferindo dos demais. Já os animais de pelagem baia praticamente não buscaram a sombra entre os turnos de avaliação.

\section{Discussão}

Os animais tendem a realizar o pastejo preferencialmente após o amanhecer e antes do entardecer, em função do comportamento natural que dita questões de sobrevivência, fazendo com que estes colham o alimento durante as horas de maior luminosidade para a noite ficarem em alerta contra os predadores (Van Soest, 1994), o que resulta em menores tempos de ruminação nos períodos da manhã e da tarde, consequência da etologia dos animais na distribuição das atividades (Fonseca et al., 2017).

No período do verão, durante as horas mais quentes do dia, os requerimentos absolutos por nutrientes específicos, os processos fisiológicos e o metabolismo do animal tendem a reduzir o consumo total de matéria seca pelo animal (Cunningham e Klein, 2008), o que pode ser observado na Figura 1 , que mostra uma tendência de pastejo durante os períodos com temperaturas mais amenas.

A equilibrada distribuição entre os períodos de pastejo e ruminação pode ter sido influenciada pela estrutura do dossel forrageiro, uma vez que quanto maior a participação de alimentos volumosos na dieta, maior será o tempo despendido com ruminação (Van Soest, 1994).

0 tempo de pastejo é uma variável que pode ser um dos indicativos de oferta de forragem, já que quanto maior tal oferta, menor será o tempo de pastejo, e dessa forma o animal pode selecionar mais, demandando menor tempo para o deslocamento (Gontijo Neto et al., 2006).

Mercês et al. (2012), ao trabalharem com vacas mestiças leiteiras em sistema de produção a pasto, concluíram que a partir das $10 \mathrm{~h}$ os animais reduzem a atividade de pastejo e aumentam o pico de ruminação e, em menor escala, o comportamento de ócio.

Os animais têm o hábito de ruminar mais durante 
o período noturno (Polli et al., 1996), horário com temperaturas amenas; entretanto, mesmo não tendo sido avaliado o turno da noite neste experimento, pode-se considerar a relação pastejoruminação como equilibrada, uma vez que, mesmo a distribuição da atividade de ruminação sendo influenciada pela alimentação, quando os animais estão em um ambiente favorável esta se processa logo após a ingestão do alimento (Polli et al., 1996), conforme verificado neste estudo (Figura 1).

A redução no consumo de alimento é maior quanto mais intenso é o estresse térmico, resultado da inibição realizado pelo calor, no centro do apetite, localizado no hipotálamo, em função da hipertermia corporal estabelecida (Porcinatto et al., 2009).

0 tempo gasto com a atividade de ruminação varia de acordo com o animal e a dieta, e não é feita em um único momento, mas distribuída em períodos uniformes ao longo do dia, onde bovinos geralmente gastam 8 horas/dia com esta atividade (Reece, 1996).

Fonseca et al. (2017) dizem que menores tempos de ruminação observados no período da manhã e da tarde não estão relacionados ao estresse térmico, mas sim à ocorrência de pastejo e outras atividades relacionadas à etologia dos animais.

Várias características do pelame são desejáveis na criação de bovinos durante os meses mais quentes do ano, como pêlos curtos e assentados, alta densidade numérica de pêlos, maior diâmetro destes, pele pigmentada e o pelame claro (Porcinatto et al., 2009). Essas características permitem maior proteção contra a radiação solar e o estresse térmico, contribuindo para maior conforto dos animais e, consequentemente, melhor desempenho zootécnico em condições de campo (Silva, 2000).

Animais de pelagem escura apresentam maior absorção e menor reflexão da radiação térmica, o que resulta em maior estresse térmico quando comparados aos animais de pelagem clara, os quais apresentam maior penetração da radiação solar (Porcinatto et al., 2009).

A sombra disponível no ambiente, sendo ela natural ou artificial, é de fundamental importância para que os animais expressem de forma adequada seus comportamentos. Em situações nas quais o ambiente está desprovido de sombra, as altas temperaturas e umidade relativa do ar geram desconforto térmico nos animais e levam ao consequente estresse calórico (Broom e Frasier, 2010).

\section{Conclusão}

O turno de avaliação e a pelagem dos animais são dois fatores que influenciam no comportamento ingestivo de vacas nulíparas a campo. No turno do meio-dia os animais tendem a cessar o consumo de alimento, o que é mais significativo quando os animais são de pelagem preta.

\section{Referências}

Bremm C, Silva JHS, Rocha MG, Elejalde DAG, Oliveira Neto RA, Confortin ACC. Comportamento ingestivo de ovelhas e cordeiras em pastagem de azevém-anual sob níveis crescentes de suplementação. $\mathrm{R}$ Bras Zootec. 2008;37(12):2097-106.

Broom DM, Frasier AF. Comportamento e Bem-estar de Animais Domésticos. 4 ed. Barueri: Manole; 2010. 438 p.

Brown-Brandl TM, Nienaber JA, Eigenberg RA, Mader TL, Morrow JL, Dailey JW. Comparison of heat tolerance of feedlot heifers of different breed. Livest Sci. 2006;105(1-3):19-26.

Cunningham JG, Klein BG. Tratado de fisiologia veterinária. 4 ed. Rio de Janeiro: Guanabara Koogan; 2008. 710 p.

Del-Claro K. Introdução à ecologia comportamental - Um manual para o estudo do comportamento animal. Rio de Janeiro: Technical Books; 2010. 128 p.

Faria LAN, Barbosa OR, Zeoula LM, Aguiar SC, Prado RM, Bertolini DA. Produto à base de própolis (LLOS) na dieta de bovinos inteiros confinados: comportamento animal e respostas sanguíneas. Acta Sci Anim Sci. 2011;33(1):79-85.

Fonseca JDR, Pereira KCB, Carvalho CCS, Ruas JRM, Menezes GCC, Castro ALO, et al. Pastejo x Ruminação de Vacas F1 HXZ na Fase de Lactação - Zootec, Santos SP. [acesso 30 mai 2017]. Disponível em: https://tinyurl. com/y8pszwme. 
Gonyou HW. Why the study of animal behavior is associated with the animal welfare issue. J Anim Sci. 1994;72(8):2171-7.

Gontijo Neto MM, Euclides VPB, Nascimento Jr D, Miranda LF, Fonseca DM, Oliveira MP. Consumo e tempo diário de pastejo por novilhos Nelore em pastagem de capimtanzânia sob diferentes ofertas de forragem. R Bras Zootec. 2006;35(1):60-6.

INMET - Instituto Nacional de Meteorologia. [acesso 10 jan 2017]. Disponível em: https://tinyurl.com/cvm3gvu.

Jamieson WS, Hodgson J. The effect of variation in sward characteristics upon the ingestive behavior and herbage intake of calves and lambs under continuous stocking management. Grass Forage Sci. 1979;34(4):273-82.

Júnior S, Almeida H, Cardoso EO, Silva RR. Comportamento ingestivo de bovino a pasto. Rev Electron Vet. 2010;11(8):1-13.

Mercês LM, Marques JA, Barbosa LP, Brandão TO, Garcia MP, Costa AKA. Horário alternativo de ordenha e o comportamento ingestivo de vacas mestiças leiteiras em sistema de produção a pasto. Acta Sci. 2012;34(2)197-202.

Pires MFA, Ferreira AM Estresse calórico em bovinos de leite. Cad Tec Vet Zootec. 1999;(29):23-37.

Polli VA, Restle J, Senna DB, Almeida RS. Aspectos relativos à ruminação de bovinos e bubalinos em regime de confinamento. R Bras Zootec. 1996;25(5)987-93.

Porcinatto MAF, Fernandez AM, Saran Netto A, Santos MV. Influência do estresse calórico na qualidade e na produção de leite. Rev Acad Cienc Agrar Ambient. 2009;7(4):483-90.

Reece WO. Fisiologia de animais domésticos. São Paulo: Roca; 1996. 351 p.

Silva FAS, Azevedo CAV. The Assistat Software Version 7.7 and its use in the analysis of experimental data. Afr J Agric Res. 2016;11(39):3733-40.
Silva RG. Introdução à bioclimatologia animal. São Paulo: Nobel; 2000. 286 p.

Van Soest PJ. Nutritional ecology of the ruminant. 2 ed. Ithaca: Comstock Pub; 1994. 476 p.

Wrege MS. Atlas climático da região sul do Brasil: Estados do Paraná, Santa Catarina e Rio Grande do Sul. Brasília, DF: Embrapa; 2012. [acesso 23 jun 2017]. Disponível em: https://tinyurl.com/y9esmexs. 